\title{
Impact of human resource management practices on enterprises' competitive advantages and business performance: Evidence from telecommunication industry
}

\author{
Hung Duc Pham ${ }^{\text {a* }}$
}

\begin{tabular}{l}
${ }^{a}$ VNPT Dong Nai, Dong Nai Province, \\
\hline C H R O N I C L E \\
\hline Article history: \\
Received: September 82019 \\
Received in revised format: Sep- \\
tember 102019 \\
Accepted: October 25, 2019 \\
Available online: \\
October 25, 2019 \\
\hline Keywords: \\
Human resource management \\
practices \\
Competitive advantages \\
Business performance \\
Post and Telecommunications sec- \\
tor \\
Vietnam
\end{tabular}

\section{A B S T R A C T}

\begin{abstract}
Human resource is the core issue of socio-economic development all over the world and human resource practice can serve as a sustainable competitive advantage, which are considered central in the company's performance. In the field of telecommunications services, there exists a need for research on human resource management practices to lay the groundwork for improving the human resource management regime in enterprises, which has received great interest of both business executives and researchers. The current paper aims to assess the impact of human resource management practices on enterprises' competitive advantages and business performance for the case of Vietnam Post and Telecommunications Group enterprises. This study uses structural equation modeling with 117 parameters to be estimated when the total sample size is 773 observations. Research results show that: (1) Functional activities of human resource management, leading and encouraging changes, team and group activities, employee involvement, administrative activities are positively correlated with human resource management practices at Vietnam Post and Telecommunications Group enterprises. Moreover, the quality of human resources, human resource behavior, human resource management practices have a positive effect on the competitive advantage of human resources at Vietnam Post and Telecommunications Group enterprises. Furthermore, human resource management practices are found to have a positive effect on the business performance of Vietnam Post and Telecommunications Group enterprises.
\end{abstract}

\section{Introduction}

Human resource is the central and core issue of socio-economic development in every organization, country and territory all over the world. Within business context, according to Wright, Dunford, and Snell (2001), human resources are defined as human capital under the control of an enterprise in a direct relationship with employment and human resource management (HRM) are activities of the organization that directly manages the human capital and ensures that it is used towards achieving its goals. However, unlike other resources in the enterprise (physical and organizational capital), human capital is valuable, rare, inimitable and irreplaceable. Therefore, based on the resource-based theory, Boxall and Purcell (2011) argued that human resources have the potential to provide sustainable competitive advantage. However, Ulrich (1991), for example, provided practice-oriented perspectives, demonstrating the ways in which the author believes that human resource practice can serve as a sustainable competitive advantage (SCA). Many empirical studies have also demonstrated that SCA is only achieved by the interaction between human capital and human resource management practices (HRMP), which emphasizes the value of HRM rather than the quality of HR. This is also the basis to explain the reason why, while most businesses emphasize the importance of HR, very few businesses have succeeded in managing their HR as a source of competitive advantage; and while jobs such as training, selection and pay based on knowledge have been successful in some businesses, but not in every other business.

\footnotetext{
* Corresponding author.

E-mail address: phamhungduc@gmail.com (H. D. Pham) 
Therefore, besides researches or applications to develop HR through discovering and measuring components of HRMP such as Pfeffer and Jeffrey (1998), Singh (2004), Morrison (1996), Pathak (2005), there have also been many studies and even debates on the relationship between HR, HRMP and competitive advantages, which are considered central in the company's business performance (BP) (Porter \& Millar, 1985). Applying resource-based theory, studies (see, for example, Wright et al. (2001), Huselid (1995), Narasimha (2000), Gowen Iii and Tallon (2003), Rahimic (2013)) have integrated theories on HRM at the micro level, while proving HR as an important potential source of a company's SCA and HRMP as a sufficient condition to help the company achieve and maintain a SCA. However, so far, there does not appear to be in-depth studies that comprehensively examine/measure the role of HRMP (components of HRMP) to the competitive advantage in relation to the company's BP, which are considered as the goal of HRMP and also the overall goal of the company. In the field of telecommunications services, the development of information technology in the context of globalization and integration has made telecommunications services an important economic sector in every country. On the other hand, competition in the context of integration has made HR the most important resource determining the competitive advantage of enterprises. Therefore, the need for research on HRMP to lay the groundwork for improving the HRMP regime in enterprises, especially in the field of telecommunications services, has received great interest of both business executives and researchers.

The current paper aims to: (i) identify components of HRMP; competitive advantages of HR and BP of enterprises belonged to the Vietnam Post and Telecommunications Group (VNPT) across provinces and cities; (ii) develop scales for components of HRMP, competitive advantages in HR and BP of VNPT enterprises, and (iii) build and test the scale model and the theoretical model on the relationship between HRMP, competitive advantages and BP of VNPT enterprises, and on that basis, position the intensity of the interaction between these factors. The paper is structured as follows. The second section is about conceptual framework that reviews HRMP, the relationship between HRMP and SCA, and then with BP. Section 3 presents research design, which discusses research sample, research methods. Section 4 is about research results and section 5 concludes.

\section{Conceptual framework}

\subsection{Human resource management practices}

So far there are many definitions of HRMP (see for example: Rynes, Giluk, and Brown (2007), Barney (1991), Barney (1995), and Lado and Wilson (1994), Wright et al. (2001)). Studies around the world and in Vietnam (see, for example: Pfeffer and Jeffrey (1998); Singh (2004); Morrison (1996); Thang and Quang (2005a); Singh (2004); and Trần et al. (2010)) showed that the measurement components of HRMP identified in centralized research models reflect the functional activities of HRMP, which are job identification; recruitment and selection; training and development; job performance review; career planning and promotion opportunities; remuneration and bonus. Therefore, the $\mathrm{H}_{1}$ hypothesis is proposed as follows:

\section{$H_{1}$ : Functional activities of HRM are positively correlated with HRMP}

In addition, depending on the level of economic development in each country, cultural characteristics, management method, industry, type of business and the opinion of researchers, etc., each model of resource management also has some other components (see, for example: Singh (2004); Pfeffer and Jeffrey (1998); Morrison (1996); Thang and Quang (2005a); Pfeffer and Jeffrey (1998), and Thang and Quang (2005b); Pathak (2005); Warner-Smith, Loxton, and Brown (2007)). We have the following observations:

Firstly, under current conditions of deep integration into the global economy and increasing competition, which has made the business environment fluctuate incessantly (Snow \& Snell, 1993), HRMP in enterprises in general, especially enterprises operating in areas are subject to pressures of changes in science and technology such as telecommunications and besides their functional operations, need to lead and encourage employees to become innovate through creative activities that encourage employees to propose new ideas; promote technical initiatives and improvements, innovate working methods; diversify work vertically and horizontally to increase adaptability to specific requirements of the business environment such as: assigning new tasks; staff and job rotation, etc. That is, leading and encouraging changes should be a component of HRMP. Therefore, the $\mathrm{H}_{2}$ hypothesis is proposed as follows:

\section{$\mathrm{H}_{2}$ : Leading and encouraging changes are positively correlated with HRMP.}

Second, although knowledge is created by individuals, maintaining competitive advantages is a result of group actions. Companies fail not because they have no knowledge, but because of lack of architectural knowledge about the way components are integrated and linked together into a unified whole (Henderson \& Clark, 1990). Meanwhile, according to Ooi and Arumugam (2006), joining a working group and continuous and flexible learning are important factors for the organization's success in achieving collaboration between employees and managers; team work reduces employees' absenteeism and leaving the organization and increases the extent to which it accomplishes its goals (Tennant \& Langford, 2006); employees find job satisfaction and greater self-control when working in teams and groups (Ascigil \& Magner, 2009); the key to success for Japanese companies is that they work together (Silos, 1999). Therefore, team and group activities should be a component of HRMP and thus the $\mathrm{H}_{3}$ hypothesis is proposed as follows: 
$H_{3}:$ Team and group activities are positively correlated with HRMP.

Third, the function of HRM is a strategic management function, in which the top management of the organization creates sufficient conditions at a high level to satisfy employee engagement (Rahimic, 2013). The well-known HRM model (Harvard model) defines employee involvement, in which the most important is the participation in decision making in the company's business processes, which is one of four components of HRM (Rahimic, 2013). Moreover, employee involvement is a component of Singh (2004)'s model of HRMP and also it has been shown in self-managed team of Pfeffer and Jeffrey (1998); socialization of Morrison (1996); information exchange of Thang and Quang (2005a). Therefore, employee involvement should be a component of HRMP, which allows the $\mathrm{H}_{4}$ hypothesis to be proposed as follows:

\section{$H_{4}:$ Employee involvement is positively correlated with HRMP.}

Fourth, consistent with the judgment of Trần et al. (2010) in a transitional economy, the legal model (the low stage of HRM), i.e. bureaucratic management is still maintained in many businesses. VNPT operates under the model of a state-owned enterprise, so its HRM model is still heavily administrative. Accordingly, HRM activities must comply with the regimes and policies of the State, the relevant ministries and the local authority's supervision, from the issues of building apparatus, appointing high-level personnel (Group level) and medium level (VNPT enterprises in provinces and cities) to other employee regimes and policies. Therefore, administrative activities include activities that comply with state regimes and policies related to employees and employers such as: personnel statistics; working conditions; labor relations, etc. In conclusion, administrative activities should be a component of HRMP, which allows the $\mathrm{H}_{5}$ hypothesis to be proposed as follows:

\section{$H_{5}:$ Administrative activities are positively correlated with HRMP.}

\subsection{HRMP and sustainable competitive advantage}

The view that HR can provide a comparative advantage is not new (see, for example, Schuler and MacMillan (1984), Ulrich (1991)). Applying the theory of resources, Flamholtz and Lacey (1981) focus directly on the skills of employees in the organization (enterprise). On the other hand, McKelvey and Zavoina (1975) has categorized organizations based on what they refers to as the members' knowledge, skills, and abilities (KSA). In favor of the above views, Wright, McMahan, and McWilliams (1994) suggest that although HRMP are not a source of SCA, they play an important role in developing and maintaining a competitive advantage through developing human capital and regulating the relationship between human capital and SCA by influencing employee behaviors as depicted in Fig. 1.

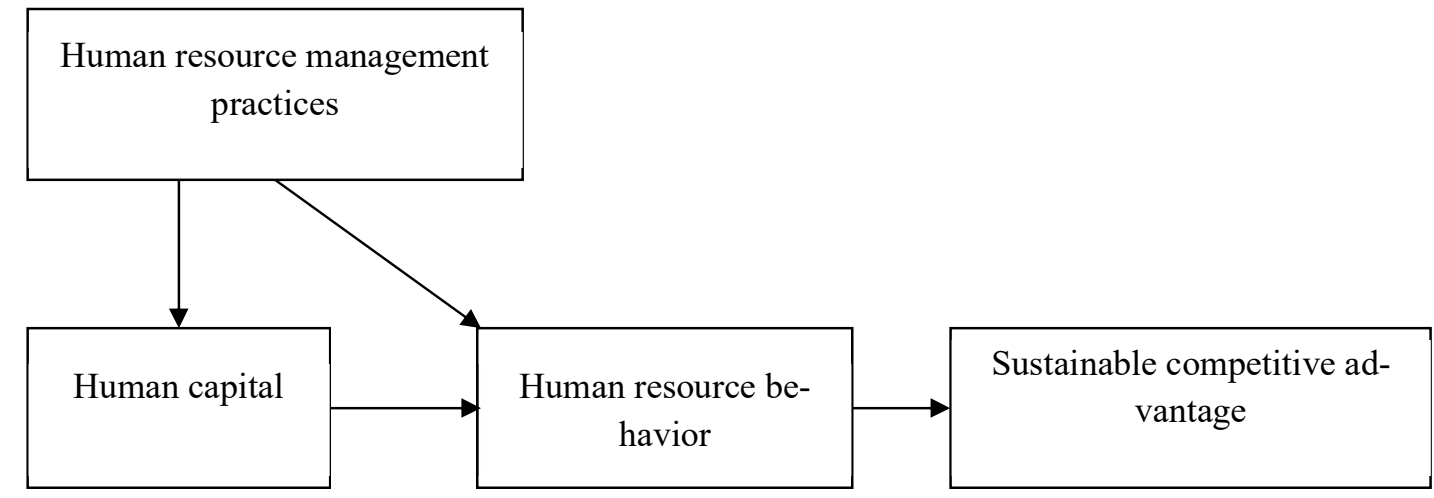

Fig. 1. Role of HRMP in maintaining competitive advantage (Source: Wright et al. (1994))

Regarding the role of the quality of HR and the behavior of HR, according to Rahimić, Sator, and Tinjić (2004), in terms of availability of physical resources, the most important component that determines a company's success is HR. In particular, the quality of HR is the central and most important component of achieving a SCA of any company. However, knowledge, skills and capabilities of employees are necessary, but not enough for employee behavior to be in line with the goals of the company (Wright \& Snell, 1991). In other words, in order to create a competitive advantage, human capital must have high level of both skills and readiness to perform through production behaviors (Wright et al., 1994). Therefore, hypotheses $\mathrm{H}_{6}$ and $\mathrm{H}_{7}$ are proposed as follows:

\section{$H_{6}$ : The quality of HR has a positive effect on the competitive advantage of HR of a business.}

\section{$H_{7}$ : Human resource behavior has a positive effect on the competitive advantage of HR of a business.}

The performance of even skilled employees may be limited, if they are not motivated to do their job. However, HRMP can affect employee motivation by encouraging them to work harder and smarter. Therefore, HRMP can affect SCA (Schuler and MacMillan (1984); Ulrich (1991)) and this is also confirmed by Martínez-del-Río, Céspedes-Lorente, and Carmona-Moreno 
(2012) that there is empirical evidence showing that companies with a high level of HRMP can benefit from cost advantages and distinct advantages. Thus, the hypothesis $\mathrm{H}_{8}$ is proposed as follows.

\section{$H_{8}: H R M P$ has a positive effect on the competitive advantage of HR of a company.}

\subsection{HRMP, SCA and business performance}

The majority of studies (for example, Buzzell, Gale, and Gale (1987); Hult et al. (2008)) suggest that firm performance is the degree to which a firm's business goals in terms of revenue growth, sales, profits, market share growth are achieved, as well as the level of completion of the firm's strategic goals. However, the problem here is whether or not the BP of a company are influenced by its HRMP and its competitive advantage?

Rahimic (2013) demonstrated that employees, in other words, knowledge, skills, abilities and motivation, as well as a sense of belonging to the company are important for BP and efficiency, thus employees that consider the company's goals as their own goals that will contribute effectively to business operations. In the study of the hotel industry, Hoque (1999) concluded that there is a reciprocal relationship between human resource quality and HRM strategies that increasingly support the focus on service quality as the source of competitive advantage. The results of Singh (2004)'s study of 359 companies in India showed that the quality of employee involvement is better and higher if there is a system of basic profit sharing-based remuneration. Therefore, based on the above research results, we can propose hypothesis $\mathrm{H}_{9}$ as follows:

\section{H9: HRMP has a positive effect on BP of a company.}

Regarding the relationship between competitive advantages and BP of enterprises, according to Porter and Millar (1985), in the case of a competitive market, competitive advantage is at the center of a company's performance. Therefore, it can be said that SCA is the strategic goal of every company, and is also a decisive factor in the company's BP. Thanks to this, the company can earn profits above the industry average and thus achieves the ultimate goal of revenue growth, sales, profit and market share growth. This is also confirmed in view of the resources of Taiwo et al. (1997) among many other researchers. Accordingly, a company can gain increased profits by developing its core competencies, because according to Ma (2000) core competencies are the deciding factor of a company's competitive advantage. Therefore, we can develop the $\mathrm{H}_{10}$ hypothesis and propose a theoretical model of the impact of HRMP on a company's competitive advantage and BP as follows (Figure 2.2).

$H_{10}$ : Competitive advantage in HR has a positive effect on the BP of a company.

Synthesizing the theories and studies of HRMP (section 2.1), HRMP and competitive advantages (section 2.2), HRMP and SCA and BP (section 2.3), we propose a theoretical model and research hypotheses on the impact of HRMP on the competitive advantage and BP of enterprises applicable to the case of VNPT as follows (Fig. 2):

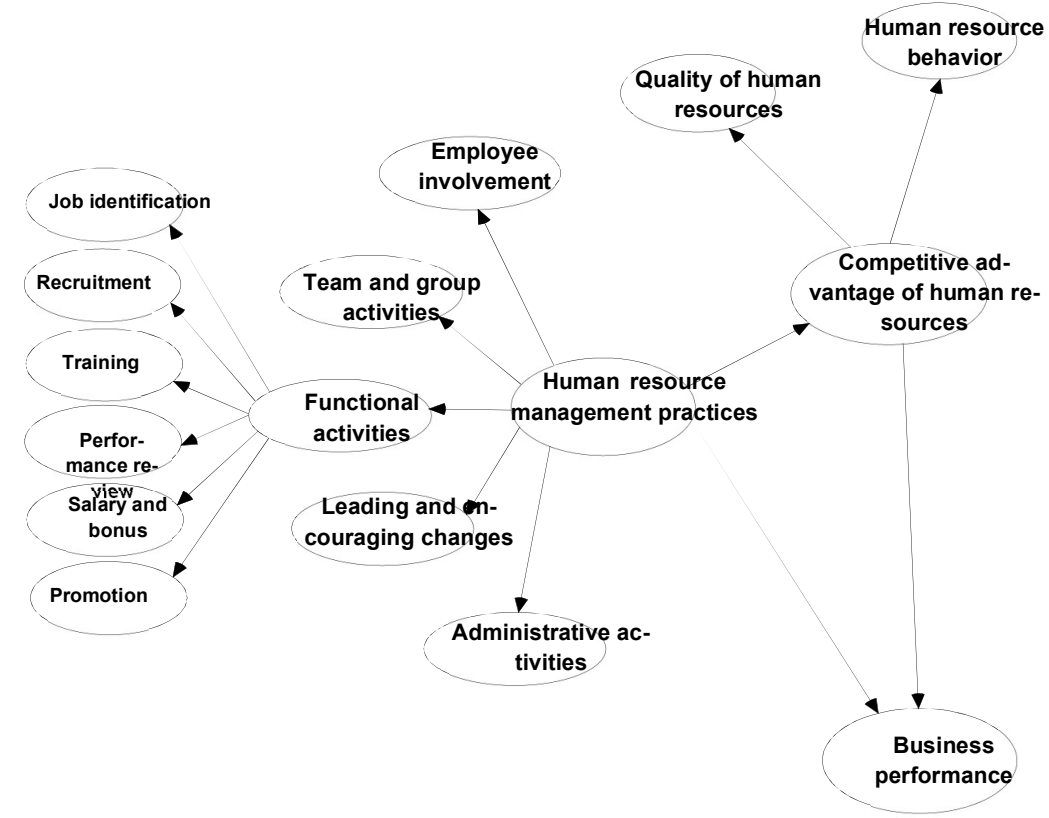

Fig. 2. Theoretical model of the impact of HRMP on competitive advantages and BP of VNPT enterprises 


\section{Research design}

\subsection{Designing research sample}

The sample was selected using a convenient sampling method, combining the norms according to the average revenue of 3 years $(2010,2011,2012)$ of telecommunication services of VNPT enterprises across all regions of the VNPT nationwide network (each region consists of a number of provinces and cities); the number of observations in each region is evenly distributed among VNPT enterprises of the three provinces and cities with average revenue of the three above years in the highest, middle and lowest rankings.

This study uses structural equation modeling (SEM), and the research model (after omitting 5 variables in the study's preliminary stage) has 117 parameters to be estimated. In order to achieve the specified sample size in case the number of observations was not fully collected, or failed due to lack of information or low quality, we decided that the number of questionnaires distributed to interview executives and employees of VNPT enterprises shall be $125 \%$ of the expected sample size (by Bollen (1990)'s rule). As a result, the distributed questionnaires are 940.

Research sample information is collected by interview techniques in three forms: direct interviews, e-mail interviews and online interviews using Google Docs from officials and employees currently working in VNPT enterprises of selected provinces and cities. Data are processed by using SPSS 16.

\subsection{Method of research data analysis}

\subsubsection{Preliminary evaluation of scales}

According to Tho and Trang (2011), in principle, the preliminary evaluation of scales has been done in the preliminary quantification, so in the official quantification we can skip it. However, if it is performed, it can help eliminate some inappropriate observed variables in advance and will be more convenient for the confirmatory factor analysis (CFA). The method to do this is completely similar to that in the preliminary quantification. However, as later stated in section 4.1, because of the large sample size $(\mathrm{N}=773)$, in the EFA process, we used Principal Axis Factoring method with Promax (Oblique) rotation and omitted observed variables with Factor loading value $\leq 0.4$ or extracted them into other factors whose Factor loading weight difference between factors $<0.3$ according to Gerbing and Anderson (1988).

\subsubsection{Validating scales with CFA}

CFA is used to validate the fit of scales to market data. The criteria for implementing a CFA include general conformity assessment criteria and conformity assessment criteria according to value attributes. In particular, to assess the goodness of fit of the model, we used the following criteria: Chi-Squared (CMIN); Chi-Squared adjusted by degrees of freedom (CMIN/df); Goodness of Fit Index (GFI); Tucker \& Lewis Index (TLI); Comparative Fit Index (CFI); Root Mean Square Error Approximation (RMSEA). The model is considered suitable when Chi-squared test has $\mathrm{P}$ value $\geq 0.05$. However, Chisquared has the disadvantage of being dependent on the sample size. The larger the sample size, the bigger the Chi-squared, which reduces the model's fit. Therefore, besides P value, CMIN/df is used. However, the CMIN/df standard limit is $<5$, as Carmines, McIver, Bohrnstedt, and Borgatta (1981) considered the CMIN/df $<2$ to be optimal; Bentler and Bonett (1980) accepted CMIN/df $\leq 3$; GFI, TLI, CFI $\geq 0.9$; RMSEA $\leq 0.08$ (RMSEA $\leq 0.05$ is considered very good, according to Steiger (1990)); while according to Thọ and Trang (2008), based on the experience of many researchers, CMIN/df $<5$ is acceptable.

Criteria for assessing the fit of a model based on value attributes include:

- Reliability of scales is assessed through $\rho_{\mathrm{c}}$ - Composite reliability coefficient (Jöreskog, 1971), $\rho_{\mathrm{vc}}$ - Variance extracted (Fornell \& Larcker, 1981) and Cronbach's Alpha $(\alpha)$ coefficient (Cronbach, 1951). In particular, the variance extracted reflects the general variance of observed variables explained by latent variables (Hair, Anderson, Tatham, \& Black, 1998); composite reliability measures the reliability of a set of observed variables that measure a concept (factor); Cronbach's alpha coefficient measures intrinsic consistency throughout the set of observed variables of answers (Schumacker, 2006). Criteria for assessing the fit of a model by the reliability of the scale are $\rho_{\mathrm{c}}>0.5$ or $\rho_{\mathrm{vc}}>0.5$ or $\alpha \geq 0.6$

- Unidimensionality of a scale represents that each observed variable can only be used to measure only one latent variable (Harris \& Schaubroeck, 1990). According to Steenkamp and Van Trijp (1991), the fit of the measurement model to market data gives us necessary and sufficient conditions to conclude that the set of observed variables achieves unidimensionality, unless errors of the set of observed variables are correlated with each other.

- Convergent validity represents that the measured values of a concept are closely correlated with each other after repeated measurements. According to Gerbing and Anderson (1988), a scale is considered to reach the convergent validity when the standardized weights of the scale are both high $(>0.5)$ and statistically significant, i.e. $\mathrm{P}<0.05$. 
- Discriminant validity represents the difference between concepts in the research model and this happens when the correlation coefficients between concepts on the overall scope are different from 1 and statistically significant $(\mathrm{P}<0.05)$.

- Nomological validity shows the compatibility between the research model and the its theoretical basis. According to Gerbing and Anderson (1988), the nomological validity is evaluated in theoretical models and according to Churchill and Peter (1995), it is considered appropriate that each measurement is related to other measurements as theoretically expected.

\subsubsection{Testing of the research model and research hypotheses}

Structural equation modeling method (SEM) is used to test the fit of theoretical models and research hypotheses. The SEM testing criteria are similar to those used in CFA analysis. However, according to Gerbing and Anderson (1988), the SEM method often requires large sample sizes, so using conventional estimation methods would be time-consuming and costly. In this case, according to Lomax and Schumacker (2004), bootstrap is a suitable alternative method, thanks to the repeated sampling with replacement, in which the original sample acts as the population (Tho \& Trang, 2008). Therefore, the bootstrap method was used to evaluate the reliability of estimated parameters in the theoretical model that has been estimated by Maximum Likelihood (ML) method.

\section{Research results}

\subsection{Research sample}

Out of 940 questionnaires distributed, we collected 812 questionnaires (86.38\%). After omitting questionnaires with lots of missing information, or with more than one answer, or being considered unreliable (having the same, or two levels of answers for all the questions), the number of questionnaires that meet the remaining criteria was $773(82.23 \%$ of the questionnaires distributed), distributed across regions of the VNPT network and demographic characteristics of interviewees (executives and employees).

\subsection{Preliminary evaluation of scales by Cronbach Alpha and EFA}

In the following part, detailed results are available on request. The results of evaluating scales by Cronbach Alpha show that the scales achieved reliability (Cronbach Alpha $>0.6$ and the item-total correlation coefficient $>0.3$ ).

The EFA results on scales measuring components of HRMP show that:

- KMO index $=0.958$ with sig $=0.000$, proving that the analytical data was suitable for EFA

- 38 observed variables were extracted into 8 factors at Eigenvalue $=1.002$ and the total variance extracted was $70.761 \%$. In particular, in addition to the 7 factors that retained the original 7 components of HRMP before the EFA, the 2 components of career planning - promotion and employee involvement were extracted into one factor. After omitting variable TT2 with unsatisfactory factor loading $(\lambda=0.344<0.4)$ and TT1 with unsatisfactory difference in factor loadings among factors $(<0.3)$, the second EFA results show that:

- $\mathrm{KMO}$ index $=0.956$ with sig $=0.000$, proving that the analytical data was suitable for EFA.

- 37 observed variables (after omitting TT1 and TT2) were extracted into 8 factors the same as the first EFA at Eigenvalue $=$ 1.001, the total variance extracted was $71.240 \%$, and re-tested Cronbach Alpha coefficients were satisfactory.

However, factors combining career planning and promotion components with variable TT4 had unsatisfactory factor loading $(\lambda=0.368<0.4)$ and variable TT3 had unsatisfactory difference in factor loadings among factors $(<0.3)$. If we had continued to eliminate variable TT4, the total variance extracted would have decreased to $69.002 \%$. If we had continued to eliminate variable TT3, the total variance extracted would have decreased to $69.032 \%$. Therefore, we decided to keep variables TT3 and TT4 for CFA.

EFA results on scales measuring components of competitive advantage of HR and BP show that:

- $\mathrm{KMO}$ index $=0.906$ with sig $=0.000$, proving that the analytical data was suitable for EFA

- 14 observed variables were extracted into 3 factors that retain the original components before conducting EFA at Eigenvalue $=1.033$ and the total variance extracted was $69.561 \%$. However, the variable CL5 had unsatisfactory difference in factor loadings among factors $(<0.3)$.

After omitting variable CL5, the second EFA results show that:

- $\mathrm{KMO}$ index $=0.895$ with sig $=0.000$, proving that the analytical data was suitable for EFA 
- 13 observed variables were extracted into 3 factors that retain the original components before conducting EFA at Eigenvalue $=1.031$ and total extracted variance reached 70,249\%, re-tested factor loadings and Cronbach Alpha coefficients were all satisfactory, so this result was accepted for inclusion in the CFA.

Thus, the results of preliminary evaluation of scales by Cronbach Alpha and EFA show that:

- The 2 observed variables TT1 and TT2 of the career planning - promotion component were omitted, the remaining 2 observed variables TT3 (creating favorable conditions for career development) and TT4 (many promotion opportunities) were merged into the employee involvement component. This is creating favorable conditions for employee involvement activities, while encouraging employees to involve in the company's business. That is, the concept of employee involvement is more universal, so we decided the name of this component after EFA shall remain the same as employee involvement.

- The remaining components measuring the concepts remain the same as before the Cronbach Alpha and EFA, but CL5 was omitted in the human resource quality's scale.

As a result, the research hypotheses remained the same as before Cronbach Alpha and EFA, but compared to before the official study (Figure 2.3), the career planning-promotion component was excluded from the research model.

\subsection{Scale validation using $C F A$}

\subsubsection{CFA results on scales measuring HRMP}

In the following part, detailed results are available on request. The standardized CFA results on scales measuring HRMP show that the model fit's basic indices including Chi-squared/df $(=5.380)$, GFI $(=0.803)$ and TLI $(=0.889)$ are not satisfactory, proving that the model did not fit the market data sufficiently well.

After omitting variables (TD2, TD3, DT1, LT1, TG3, DN2, MT3) with high correlation between errors (Modification Index - MI), the 2nd CFA results found that, although $\mathrm{p}<0.05(=0.001)$, Chi-squared/df $(=2.882)$, GFI $(=0.927)$, TLI (=0.961), CFI (=0.967) and RMSEA (=0.049) were all satisfactory (Figure 3), proving the fit of the model to market data.

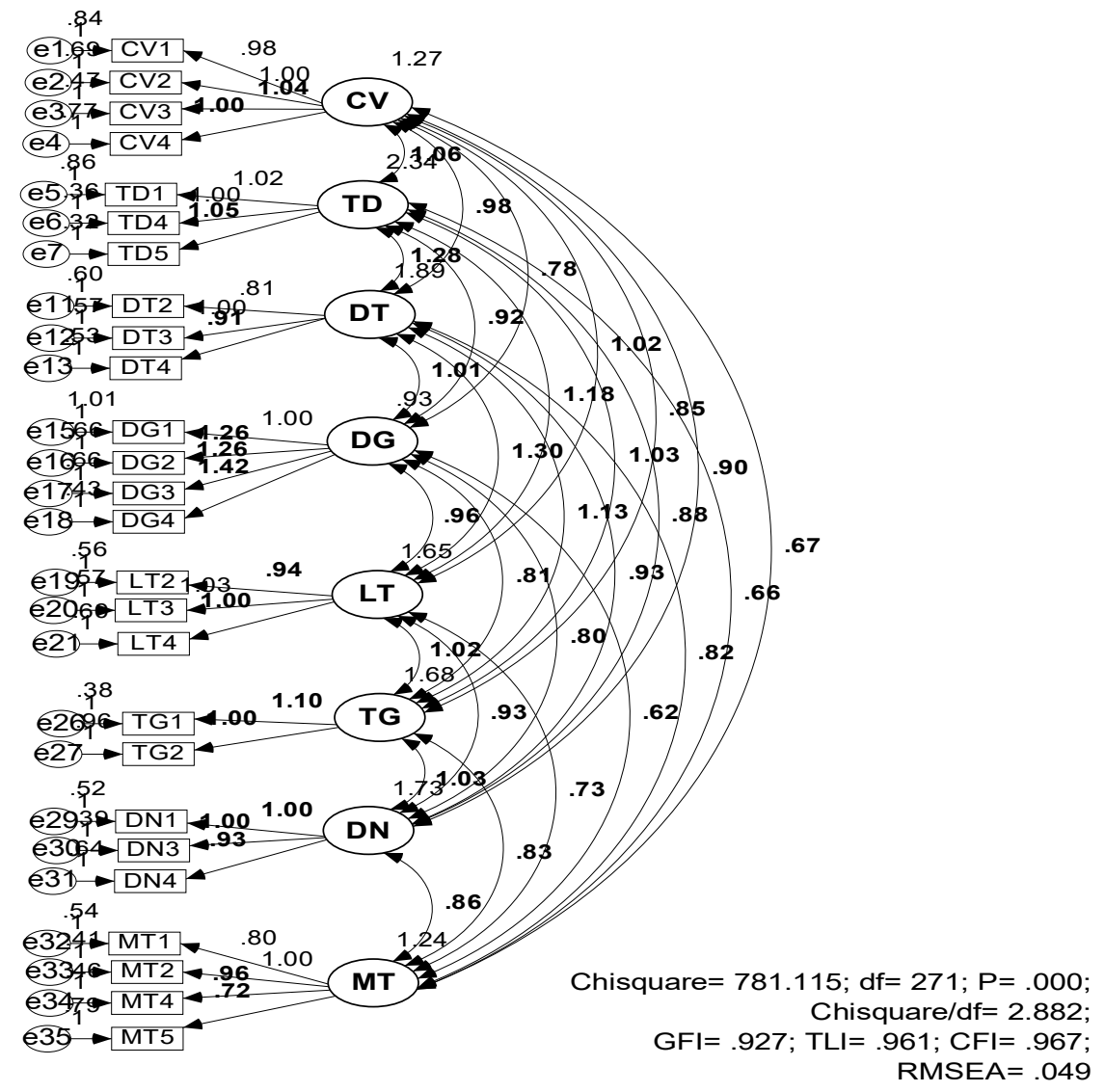

Fig. 3. CFA results on scales measuring HRMP

Source: Author's estimation from survey data 
The standardized regression weights were all greater than 0.5 (the lowest was $\lambda_{\mathrm{DG} 1}=0.694$ ) and statistically significant $(\mathrm{p}$ $<0.001$ ), proving that the observed variables of the scales had convergent validity.

The correlation coefficients between components of HRMP were less than 1 (the highest is DG $\leftrightarrow$ LT $=0.777$ ) and statistically significant $(\mathrm{p}<0.001)$, demonstrating that the components of HRMP had discriminant validity.

The scales had satisfactory composite reliability, variance extracted and Cronbach Alpha coefficient, demonstrating the value and reliability of the scales measuring HRMP.

ML estimation results on error variance of parameters to be estimated and the concepts in the model showed no Heywood case (Heywood, 1931) in any error and all standard errors were $<|2.58|$. Therefore, CFA results on scales measuring HRMP were accepted.

\subsubsection{CFA results on scales measuring SCA of human resources}

In the following part, detailed results are available on request. The CFA results on scales measuring competitive advantages of HR and BP show that the model fit's basic indices including GFI $(=0.938)$, TLI $(=0.945)$ and CFI $(=0.962)$ were all satisfactory. However, Chi-squared/df $(=10,432)$, and RMSEA $(=0.111)$ were unsatisfactory, and many Modification Indexes (MI) measuring the correlation between errors of variables were still very high, so the scales did not have unidimensionality.

After omitting the variables (CL3, HV2) with high MI, the second CFA results showed that, although p $<0.05(=0.001)$ and Chi-squared/df index were quite high $(=4.873)$, GFI $(=0.985)$, TLI $(=0.981)$, CFI $(=0.990)$ and RMSEA $(=0.071)$ were all satisfactory (Figure 4.2), proving the model's fit to market data.

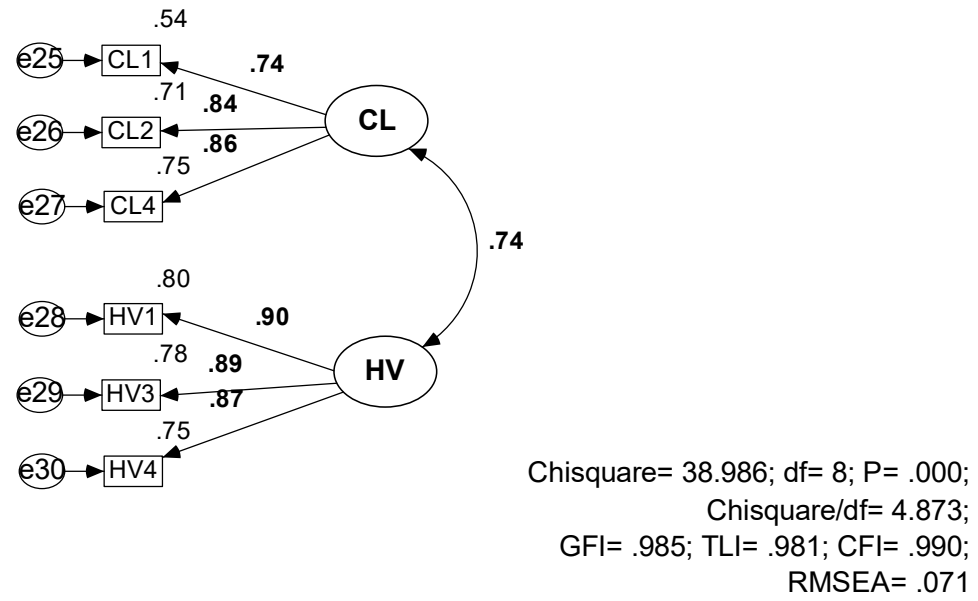

Fig. 4. CFA results on scales measuring competitive advantage of HR

Source: Author's estimation from survey data

The standardized regression weights were all greater than 0.5 (the lowest was $\lambda_{\mathrm{CL} 1}=0.735$ ) and statistically significant ( $\mathrm{p}$ $<0.001$ ), proving that the scales had convergent validity.

The correlation coefficient between the two components of the concept of competitive advantage of HR was less than 1 (CL $\leftrightarrow$ $\mathrm{HV}=0.742)$ and statistically significant $(\mathrm{p}<0.001)$, proving the components of competitive advantage had discriminant validity.

The scales had satisfactory composite reliability, variance extracted and Cronbach Alpha coefficient, demonstrating the value and reliability of the scales measuring competitive advantage of HR.

ML estimation results on error variance of parameters to be estimated and the concepts in the model showed no Heywood case (Heywood, 1931) in any error and all standard errors were $<|2.58|$. Therefore, CFA results on scales measuring competitive advantage of HR were accepted.

\subsubsection{CFA results of the saturated model}

In the following part, detailed results are available on request. The CFA results of the saturated model showed that only the model fit's basic indices including TLI $(=0.911)$, CFI $(=0.917)$ and RMSEA $(=0.063)$ were satisfactory. However, Chi- 
squared/df $(=4,088)$ was still quite high and GFI $(=0.841)$ was not satisfactory, and many Modification Indexes (MI) measuring the correlation between errors of variables were still very high (Detailed results available on request), so the scales did not have unidimensionality.

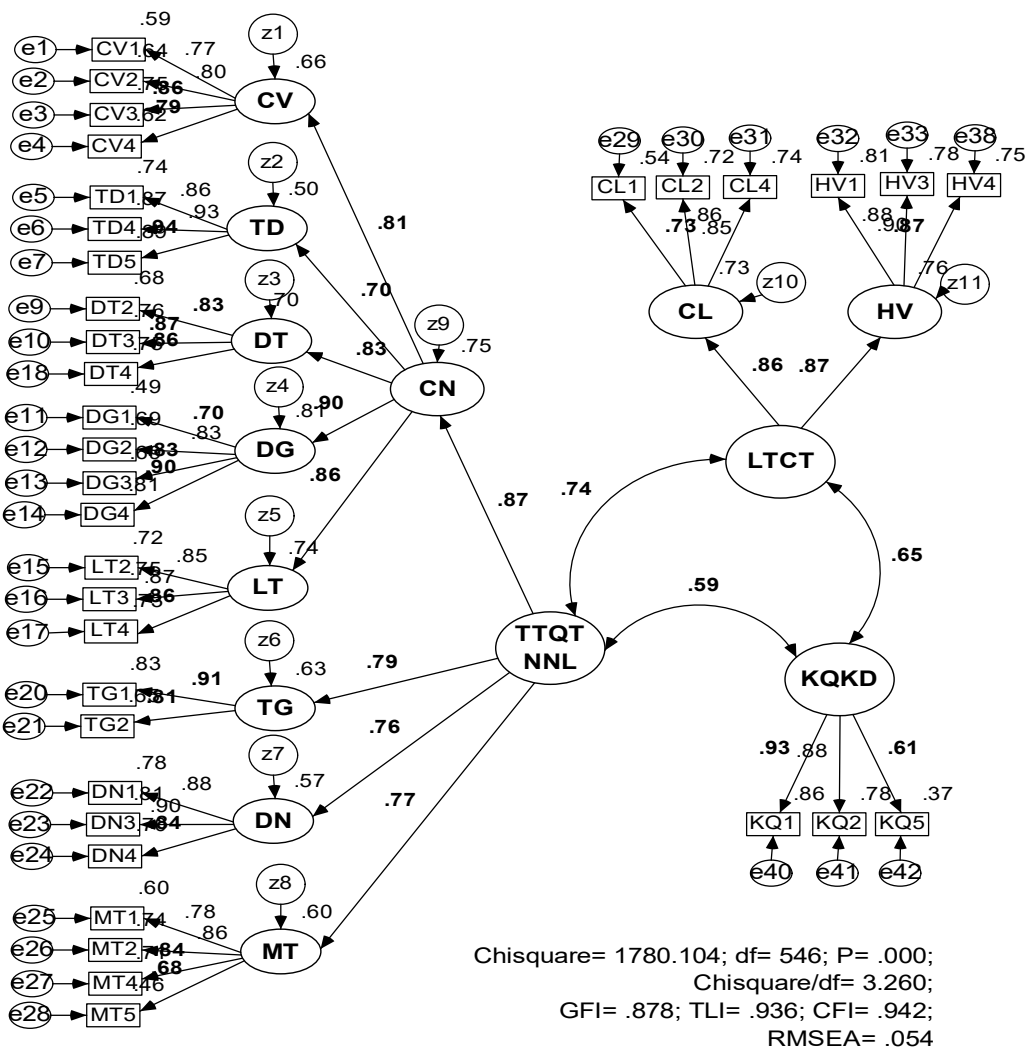

Fig. 5. CFA results of the saturated model

Source: Author's estimation from survey data

After omitting variables KQ3 and KQ4, the second CFA results showed that, although $\mathrm{p}<0.05(=0.000)$; Chi-squared/df $(=$ $3,260)$ was still relatively high; GFI $(=0.878)$ was lower than the standard $(>0.9)$, but TLI $(=0.936$, CFI $(=0.942)$ and RMSEA (=0.054) were all satisfactory (Figure 4.3), proving the model's fit to market data. The standardized regression weights were all greater than 0.5 (the lowest was $\left.\lambda_{\mathrm{KQ} 5}=0.608\right)$ and statistically significant $(\mathrm{p}<0.001)$, proving that the observed variables of the scales had convergent validity. The correlation coefficients between the concepts were less than 1 $(\mathrm{QTNNL} \leftrightarrow \mathrm{LTCT}=0.736 ; \mathrm{QTNNL} \leftrightarrow \mathrm{KQKD}=0.593 ; \mathrm{KQKD} \leftrightarrow \mathrm{LTCT}=0.650)$ and statistically significant $(\mathrm{p}<0.001)$ proving the concepts of the model had discriminant validity (Detailed results available on request). The scales had satisfactory composite reliability, variance extracted and Cronbach Alpha coefficient, demonstrating the value and reliability of the scales measuring concepts in the theoretical model. ML estimation results on error variance of parameters to be estimated and the concepts in the model showed no Heywood case (Heywood, 1931) in any error and all standard errors were $<|2.58|$. Therefore, CFA results on scales measuring concepts in the saturated model were accepted.

\subsection{Validation of the research model}

\subsubsection{Formal validation of the theoretical model using SEM}

In the following part, detailed results are available on request. The SEM results of the theoretical model (Figure 4.4) showed that it was similar to the saturated model: $\mathrm{p}=0.000 ;$ Chi-squared $/ \mathrm{df}=3,260 ; \mathrm{GFI}=0.878 ; \mathrm{TLI}=0.936 ; \mathrm{CFI}=0.942$, RMSEA $=0.054$; standardized regression weights were all satisfactory $(>0.5)$; the scales' composite reliability, variance extracted and Cronbach Alpha coefficient were all satisfactory $(>0.5)$; error variance of parameters to be estimated and the concepts in the model showed no Heywood case (Heywood, 1931) in any error and all standard errors were $<|2.58|$. Therefore, it was possible to conclude that there was a good fit of the theoretical model to market data. The results of (standardized) estimation of the main parameters in the model (detailed results are available on request) all reached a certain value and had statistical significance $(\mathrm{p} \leq 0.05)$. This showed that "each measurement was related to the other as theoretically expected" (Churchill \& Peter, 1995). That means that the scales measuring the concepts in the model met the criteria for theoretical reference values. 


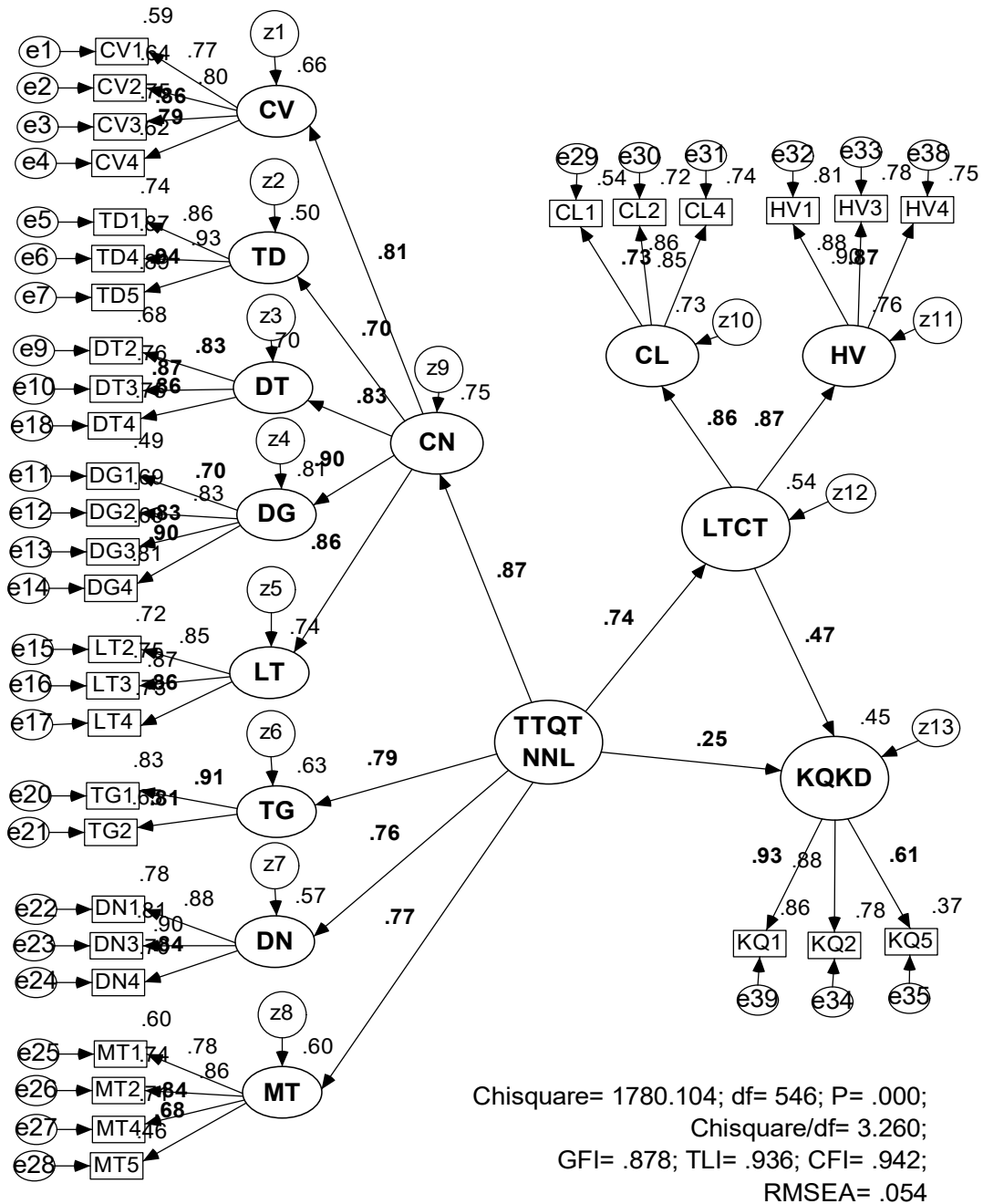

Fig. 6. SEM results of formal (standardized) theoretical model (Source: Author's estimation from survey data)

\subsubsection{Validation and estimation of the theoretical model by bootstrap method}

In this study, the bootstrap estimation was performed by repeated sampling with $N=1500$. The estimation results (Table 1) shows that the bias and the standard error of the bias (SE-Bias) between bootstrap estimation and optimal ML estimation used in the verification study appeared, but SE-Bias was not statistically significant, proving that the estimated results in this study was reliable.

Table 1

Bootstrap estimation vs. ML estimation results

\begin{tabular}{|c|c|c|c|c|c|c|c|}
\hline \multirow{2}{*}{ Relation } & \multicolumn{2}{|c|}{ ML estimation } & \multicolumn{3}{|c|}{ Bootstrap estimation } & \multicolumn{2}{|c|}{ Difference } \\
\hline & Mean & SE & Mean & $\mathrm{SE}$ & $\mathrm{SE}(\mathrm{SE})$ & Bias & SE (Bias) \\
\hline$\rightarrow \mathrm{CV}$ & 0.814 & & 0.814 & 0.023 & 0.000 & 0.000 & 0.001 \\
\hline$\rightarrow \mathrm{TD}$ & 0.704 & 0.077 & 0.704 & 0.025 & 0.000 & -0.001 & 0.001 \\
\hline$\rightarrow \mathrm{DT}$ & 0.835 & 0.060 & 0.834 & 0.019 & 0.000 & -0.001 & 0.000 \\
\hline$\rightarrow \mathrm{DG}$ & 0.900 & 0.066 & 0.899 & 0.017 & 0.000 & -0.001 & 0.000 \\
\hline $\mathrm{CN} \quad \rightarrow \mathrm{LT}$ & 0.861 & 0.064 & 0.860 & 0.017 & 0.000 & -0.001 & 0.000 \\
\hline TTQTNNL $\rightarrow$ CN & 0.866 & & 0.865 & 0.022 & 0.000 & -0.001 & 0.001 \\
\hline TTQTNNL $\rightarrow$ TG & 0.793 & 0.092 & 0.793 & 0.024 & 0.000 & 0.000 & 0.001 \\
\hline TTQTNNL $\rightarrow$ DN & 0.755 & 0.085 & 0.756 & 0.027 & 0.000 & 0.000 & 0.001 \\
\hline TTQTNNL $\rightarrow$ MT & 0.744 & 0.062 & 0.775 & 0.030 & 0.001 & 0.001 & 0.001 \\
\hline LTCT $\quad \rightarrow \quad$ CL & 0.855 & & 0.856 & 0.033 & 0.001 & 0.000 & 0.001 \\
\hline LTCT $\rightarrow \mathrm{HV}$ & 0.869 & 0.079 & 0.867 & 0.022 & 0.000 & -0.002 & 0.001 \\
\hline TTQTNNL $\rightarrow$ LTCT & 0.736 & 0.053 & 0.736 & 0.036 & 0.001 & 0.001 & 0.001 \\
\hline TTQTNNL $\rightarrow$ KQKD & 0.249 & 0.086 & 0.249 & 0.068 & 0.001 & 0.000 & 0.002 \\
\hline LTCT $\rightarrow$ KQKD & 0.468 & 0.102 & 0.467 & 0.075 & 0.001 & 0.000 & 0.002 \\
\hline
\end{tabular}

Note: Mean: average estimated value; SE: standard error; SE (SE): standard error of standard error; Bias: bias; SE (Bias): standard error of bias

Source: Author's estimation from survey data 


\subsubsection{Conclusion on validation of research hypotheses}

The results of estimating parameters by ML and Bootstrap methods in Table 4.1 showed that the relationships between the concepts in the theoretical model were in the same direction (positive sign) as determined in the research hypotheses and statistically significant ( $<<0.001$ ), proving that the following research hypotheses $\left(\mathrm{H}_{1}, \mathrm{H}_{2}, \mathrm{H}_{3}, \mathrm{H}_{4}, \mathrm{H}_{5}, \mathrm{H}_{6}, \mathrm{H}_{7}, \mathrm{H}_{8}, \mathrm{H}_{9}\right)$ were accepted.

\section{Conclusion}

Human resource (HR) is the central issue of socio-economic development of all organizations, countries and territories. Within business context, HR are defined as human capital having a direct relationship with employment and human resource practices. In addition, HR have the potential to provide SCA, which are considered central in the company's performance. The current paper has aimed to assess the impact of human resource management practices on enterprises' competitive advantages and business performance for the case of Vietnam Post and Telecommunications Group enterprises. This study used structural equation modeling (SEM) with 117 parameters to be estimated when the total sample size was 773 observations. Research results have shown that: (1) Functional activities of HRM, leading and encouraging changes, team and group activities, employee involvement, administrative activities were positively correlated with HRMP at VNPT enterprises. Moreover, the quality of HR, human resource behavior, HRMP have a positive effect on the competitive advantage of HR at VNPT enterprises. Furthermore, HRMP are found to have a positive effect on the BP of VNPT enterprises.

\section{References}

Ascigil, S. F., \& Magner, N. R. (2009). Business incubators: leveraging skill utilization through social capital. Journal of Small Business Strategy, 20(1), 19-34.

Barney, J. (1991). Firm resources and sustained competitive advantage. Journal of management, 17(1), 99-120.

Barney, J. B. (1995). Looking inside for competitive advantage. Academy of Management Perspectives, 9(4), 49-61.

Bentler, P. M., \& Bonett, D. G. (1980). Significance tests and goodness of fit in the analysis of covariance structures. Psychological bulletin, 88(3), 588 .

Bollen, K. A. (1990). Overall fit in covariance structure models: Two types of sample size effects. Psychological bulletin, 107(2), 256.

Boxall, P., \& Purcell, J. (2011). Strategy and human resource management: Macmillan International Higher Education.

Buzzell, R. D., Gale, B. T., \& Gale, B. T. (1987). The PIMS principles: Linking strategy to performance: Simon and Schuster.

Carmines, E. G., McIver, J. P., Bohrnstedt, G. W., \& Borgatta, E. F. (1981). Social measurement: Current issues. Analyzing models with unobserved variables: Analysis of covariance structures, 80, 65-115.

Churchill, G. A., \& Peter, J. P. (1995). Marketing: Creating value for customers: Irwin Boston.

Cronbach, L. J. (1951). Coefficient alpha and the internal structure of tests. Psychometrika, 16(3), 297-334.

Flamholtz, E., \& Lacey, J. (1981). Personnel Management, Human Capital Theory, and Human Resource Accounting. Los Angeles: Inst. Ind. Relat., Univ. Calif.

Fornell, C., \& Larcker, D. F. (1981). Structural equation models with unobservable variables and measurement error: Algebra and statistics. In: SAGE Publications Sage CA: Los Angeles, CA.

Gerbing, D. W., \& Anderson, J. C. (1988). An updated paradigm for scale development incorporating unidimensionality and its assessment. Journal of marketing research, 25(2), 186-192.

Gowen Iii, C. R., \& Tallon, W. J. (2003). Enhancing supply chain practices through human resource management. Journal of Management Development, 22(1), 32-44.

Hair, J. F., Anderson, R. E., Tatham, R. L., \& Black, W. C. (1998). Multivariate data analysis. Englewood Cliff. New Jersey, USA, 5(3), 207-2019.

Harris, M. M., \& Schaubroeck, J. (1990). Confirmatory modeling in organizational behavior/human resource management: Issues and applications. Journal of Management, 16(2), 337-360.

Henderson, R. M., \& Clark, K. B. (1990). Architectural innovation: The reconfiguration of existing. Administrative science quarterly, 35(1), 9-30.

Hoque, K. (1999). New approaches to HRM in the UK hotel industry. Human Resource Management Journal, 9(2), 64-76.

Hult, G. T. M., Ketchen, D. J., Griffith, D. A., Chabowski, B. R., Hamman, M. K., Dykes, B. J., . . Cavusgil, S. T. (2008). An assessment of the measurement of performance in international business research. Journal of International Business Studies, 39(6), 1064-1080.

Huselid, M. A. (1995). The impact of human resource management practices on turnover, productivity, and corporate financial performance. Academy of management journal, 38(3), 635-672.

Jöreskog, K. G. (1971). Simultaneous factor analysis in several populations. Psychometrika, 36(4), 409-426.

Lado, A. A., \& Wilson, M. C. (1994). Human resource systems and sustained competitive advantage: A competency-based perspective. Academy of management review, 19(4), 699-727.

Lomax, R. G., \& Schumacker, R. E. (2004). A beginner's guide to structural equation modeling: psychology press.

Ma, H. (2000). Competitive advantage and firm performance. Competitiveness Review: An International Business Journal, 10(2), $15-32$.

Martínez-del-Río, J., Céspedes-Lorente, J., \& Carmona-Moreno, E. (2012). High-involvement work practices and environmental capabilities: How HIWPS create environmentally based sustainable competitive advantages. Human resource management, $51(6), 827-850$. 
McKelvey, R. D., \& Zavoina, W. (1975). A statistical model for the analysis of ordinal level dependent variables. Journal of mathematical sociology, 4(1), 103-120.

Morrison, E. W. (1996). Organizational citizenship behavior as a critical link between HRM practices and service quality. Human resource management, 35(4), 493-512.

Narasimha, S. (2000). Organizational knowledge, human resource management, and sustained competitive advantage: Toward a framework. Competitiveness Review: An International Business Journal, 10(1), 123-135.

Ooi, K. B., \& Arumugam, V. (2006). The influence of corporate culture on organizational commitment: case study of semiconductor organizations in Malaysia. Sunway Academic Journal, 3, 99-115.

Pathak, R. (2005). Flexibility-thinking shift for organizational excellence. Global Journal of Flexible Systems Management, 6(3/4), 59.

Pfeffer, J., \& Jeffrey, P. (1998). The human equation: Building profits by putting people first: Harvard Business Press.

Porter, M. E., \& Millar, V. E. (1985). How information gives you competitive advantage. In: Harvard Business Review Reprint Service.

Rahimić, M., Sator, A., \& Tinjić, L. (2004). Obesity is a disease--the" School of Healthy Weight Loss" is therapeutic. Medicinski arhiv, 58(1 Suppl 1), 57-59.

Rahimic, Z. (2013). Influence of organizational climate on job satisfaction in Bosnia and Herzegovina companies. International Business Research, 6(3), 129.

Rynes, S. L., Giluk, T. L., \& Brown, K. G. (2007). The very separate worlds of academic and practitioner periodicals in human resource management: Implications for evidence-based management. Academy of Management Journal, 50(5), 987-1008.

Schuler, R. S., \& MacMillan, I. C. (1984). Gaining competitive advantage through human resource management practices. Human resource management, 23(3), 241-255.

Schumacker, R. E. (2006). Teacher's Corner: Conducting Specification Searches With Amos. Structural Equation Modeling, 13(1), $118-129$.

Silos, I. M. (1999). Employee involvement--a component of total quality management. Production and Inventory Management Journal, 40(1), 56.

Singh, K. (2004). Impact of HR practices on perceived firm performance in India. Asia Pacific Journal of Human Resources, 42(3), 301-317.

Snow, C. C., \& Snell, S. A. (1993). Staffing as strategy. Personnel selection in organizations, 448, 478.

Steenkamp, J.-B. E., \& Van Trijp, H. C. (1991). The use of LISREL in validating marketing constructs. International Journal of Research in marketing, 8(4), 283-299.

Steiger, J. H. (1990). Structural model evaluation and modification: An interval estimation approach. Multivariate behavioral research, 25(2), 173-180.

Taiwo, A. S., Idunnu, F. O., Aborisade, F., Akinyele, S., Allison, M., Kaye, J., . . Armstrong, J. (1997). The impact of grand strategy and planning formality on financial performance. Research Journal of Business Management, 1(1), 221-235.

Tennant, S., \& Langford, D. (2006). Team performance measurement: Let's reward teamwork. Paper presented at the 22nd Annual ARCOM Conference.

Thang, L. C., \& Quang, T. (2005a). Antecedents and consequences of dimensions of human resource management practices in Vietnam. The International Journal of Human Resource Management, 16(10), 1830-1846.

Thang, L. C., \& Quang, T. (2005b). Human resource management practices in a transitional economy: A comparative study of enterprise ownership forms in Vietnam. Asia Pacific business review, 11(1), 25-47.

Tho, N. D., \& Trang, N. T. M. (2011). Phuong phap nghien cuu khoa hoc trong kinh doanh. Nha xuat ban Lao Dong Xa Hoi. Thanh pho Ho Chi Minh.

Thọ, N. Đ., \& Trang, N. T. M. (2008). Nghiên cứu khoa học trong quản trị kinh doanh, NXB. Thống kê, Hà Nội.

Trần, K. D., Đoàn, T. H., Lê, T. L., Bùi, T. T., Phan, Q. T., \& Huỳnh, V. T. (2010). Mối quan hệ giữa thực tiễn quản trị nguồn nhân lực, kết quả quản trị nguồn nhân lực và kết quả kinh doanh trong các doanh nghiệp.

Ulrich, D. (1991). Using human resources for competitive advantage. In R. Kilmann \& I. Kilmann (Eds.), Making Organizations Competitive. San Francisco, CA Jossey-Bass.

Warner-Smith, P., Loxton, D., \& Brown, W. J. (2007). Human resources for longitudinal studies: Matching people to skills and tasks. International Journal of Multiple Research Approaches, 1(2), 92-103.

Wright, P. M., Dunford, B. B., \& Snell, S. A. (2001). Human resources and the resource based view of the firm. Journal of Management, 27(6), 701-721.

Wright, P. M., McMahan, G. C., \& McWilliams, A. (1994). Human resources and sustained competitive advantage: a resourcebased perspective. International Journal of Human Resource Management, 5(2), 301-326.

Wright, P. M., \& Snell, S. A. (1991). Toward an integrative view of strategic human resource management. Human Resource Management Review, 1(3), 203-225.

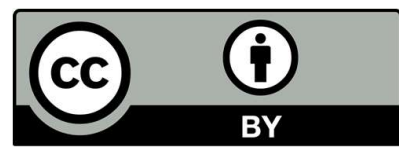

(C) 2020 by the authors; licensee Growing Science, Canada. This is an open access article distributed under the terms and conditions of the Creative Commons Attribution (CC-BY) license (http://creativecommons.org/licenses/by/4.0/). 